\title{
An Extract and Fractions from Coffea arabica Sediment on Antioxidant and Anti-Tyrosinase Activities, and on the Quality of Whiteleg Shrimp (Litopenaus vannamel) during Refrigerated Storage
}

\author{
Dao Thi Anh Phan ${ }^{1}$, Hue Thi Ha ${ }^{1}$, and Tinh Trung $\mathrm{Ho}^{2}$ \\ ${ }^{1}$ Department of Chemical Technology, Faculty of Chemical and Food Technology, \\ Ho Chi Minh City University of Technology and Education, Ho Chi Minh City 70000, Viet Nam \\ ${ }^{2}$ Department of Chemistry, Faculty of Food Science and Technology, Thu Dau Mot University, Binh Duong 59000, Viet Nam
}

\begin{abstract}
Coffea arabica sediment, a popular agro-by-product from the coffee juice processing industry, contains many phytochemicals, and it is often discarded as waste. The antioxidant and anti-tyrosinase activities of an ethanol extract and its active fractions obtained from Coffea arabica sediment was studied. Additionally, whiteleg shrimp (Litopenaeus vannamei) was treated with the extract and fractions, and the quality during refrigerated storage was evaluated. The most active fraction $(P<0.05)$ fraction III from the Coffea arabica sediment extract showed a total phenolic content of $116.5 \mathrm{mg}$ gallic acid equivalent/g, an inhibitory concentration of $50 \%$ value of $27.3 \mu \mathrm{g} / \mathrm{mL}$ in the 2,2-diphenyl-1-picryl hydrazyl test, an absorbance of 3.7 (at $1.0 \mu \mathrm{g} / \mathrm{mL}$ ) in the reducing power assay, and $79.5 \%$ inhibition for the tyrosinase inhibition test (at 100 $\mu \mathrm{g} / \mathrm{mL}$ ). Whiteleg shrimp treated with PD-3 and crude extract (CE) retarded the growth of bacteria and spoilage microorganisms in comparison to the control $(P<0.05)$. Lower values in $\mathrm{pH}$, thiobarbituric acid reactive substances, and total volatile base content were enumerated in samples treated with PD-3 and CE $(P<0.05)$ compared to controls. Loss in freshness, protein content, and melanosis formation declined with CE and PD-3 treatments. Our findings showed that Coffea arabica sediment has antioxidant and antimicrobial properties. Also, it could be a promising treatment in melanosis prevention, and a natural additive for extending the shelf life of whiteleg shrimp during refrigerated storage; thus an alternative to traditional sulfites.
\end{abstract}

Keywords: antioxidant, Coffea arabica, melanosis, tyrosinase, whiteleg shrimp (Litopenaus vannamei)

\section{INTRODUCTION}

Whiteleg shrimp (Litopenaeus vannamei) is a major commercial species accounting for $90 \%$ of the global shrimp aquaculture production (Nirmal and Benjakul, 2009) and one of the most widely consumed crustaceans in many countries (Na et al., 2018). Shrimp is highly susceptible to both endogenous enzymatic browning or melanosis, and microbial spoilage during postmortem storage, so it is pivotal to preserve shrimp properly using effective and appropriate methods (Huang et al., 2012). The common methods frequently used for shrimp preservation such as freezing, heating, a combination of brining and chilling, or adding preservatives often face serious challenges with the formation of black spots, lipid oxidation, microbial spoilage, and toxicity associated with physicochemical changes and off-flavors that all reduce the market value of shrimp and consumer acceptability (Nirmal and Benjakul, 2009; Huang et al., 2012; Arancibia et al., 2015).

Melanosis in shrimp is a defect triggered by a biochemical reaction, which catalyzes the oxidation of phenolic compounds to the corresponding quinones by the activity of tyrosinase. This process is followed by non-enzymatic polymerization, forming pigments of high weight molecules, and dark coloring in shrimp (Gokoglu and Yerlikaya, 2008; Nirmal and Benjakul, 2009). Much research has been devoted to either preventing melanosis or inhibiting tyrosinase through various techniques and mechanisms. Antibrowning agents such as sulfites and their derivatives are the most widely applied reagents for the prevention 
of melanosis in the food industry by reacting irreversibly with $o$-quinones to form colorless materials (Kuijpers et al., 2013). However, exposure to these sulfite chemicals has been documented to induce a wide range of negative clinical effects, namely urticaria, flushing, dermatitis, hypotension, diarrhea, abdominal pain, and asthmatic reactions in sensitive people (Taylor et al., 1986; Vally and Misso, 2012). The risks associated with sulfite additives have prompted a search for a safe, effective sulfite alternative in food processing. Both synthetic and natural antioxidants have been used in food applications as potential additives. Long term studies showed that synthetic antioxidant substances such as butylated hydroxyanisole, butylated hydroxytoluene, tertiary butyl hydroxyquinone, and propyl gallate could act as carcinogenic agents in animals (Barlow, 1990). Plant phenolics such as tocopherols, flavonoid compounds, cinnamic acid derivatives, and coumarins exhibit an antioxidant influence that inhibits undesirable enzymatic browning (Jayaprakasha et al., 2001; Gokoglu and Yerlikaya, 2008). Recently, a series of studies have demonstrated that grape seed extract (Gokoglu and Yerlikaya, 2008), enokitake extract (Jang et al., 2003), and edible mushroom extract (Encarnacion et al., 2012) could prevent melanosis or extend the shelf life in shrimp.

The vegetable and fruit processing industry has generated large quantities of by-products during different processing steps. They are rich in bioactive compounds, which can be utilized as novel, low-cost natural sources of antioxidants, antimicrobials, dietary fiber, enzymes, and food additives through different methods of extraction, purification, and fermentation (Gowe, 2015; Kodagoda and Marapana, 2017). In a previous study, an ethanol extract of Coffea arabica sediment proved to be one of the most efficient extracts in antioxidant activity and inhibiting tyrosinase (Hue et al., 2020), so it was studied further in this research. This study aimed to examine antioxidant activity and tyrosinase inhibition of an ethanol extract from Coffea arabica sediment and its various fractions. Secondly, the additional aim was to investigate the potential of Coffea arabica sediment extract and its most potent fraction to preserve Litopenaeus vannamei shrimp in terms of melanosis prevention, lipid peroxidation, bacterial spoilage, and physicochemical changes.

\section{MATERIALS AND METHODS}

\author{
Chemicals \\ L- $\beta$-(3,4 dihydroxylphenyl) alanine (L-DOPA), thiobarbi- \\ turic acid (TBA), Folin-Ciocalteu reagent, 2,2-diphenyl- \\ 1-picryl hydrazyl (DPPH), malondialdehyde (MDA), and \\ tyrosinase were obtained from Sigma-Aldrich Co. (St. \\ Louis, MO, USA). Trichloroacetic acid (TCA) was pur- \\ chased from Merck KGaA (Darmstadt, Germany). All
}

other chemicals used were of analytical grade.

\section{Preparation and extraction of Coffea arabica sediment}

Roasted Coffea arabica sediment is leftover juice pulp (as a solid waste) created during the juicing process. Coffea arabica sediment was bought from Long Phuoc Market, Ho Chi Minh City, Viet Nam. The material was collected, dried to constant weight, and ground to powder.

Dried powder (100 g) was immersed in ethanol (1:1.5, $\mathrm{w} / \mathrm{v}$ ) at room temperature within 6 days. The mixtures were filtered, and new solvent added to the residue every two days. The obtained extract was filtered and concentrated by a rotary evaporator to get the crude extract.

\section{Fractionation of Coffea arabica sediment extract}

The ethanol extract of Coffea arabica was fractionated into various fractions. Fractionation was conducted using a vacuum chromatography column. The column was packed with silica gel $60 \sim 200$ mesh as a stationary phase, and eluted using a mobile phase system with solvents of gradually increasing polarity. The mobile phase elution was as follows: $n$-hexane : ethyl acetate-97:3, 95:5, 90:10, $85: 15,80: 20,70: 30,60: 40,50: 50,40: 60,30: 70,20: 80$, 10:90, and 0:100. Eluate was collected in $100 \mathrm{~mL}$ fractions and combined into some fractions based on its profile using thin layer chromatography aluminum plate GF254 (Merck KGaA). The collected fractions then were tested for their antioxidant and antityrosinase activities. A total of 6 fractions were collected from the fractionation process of Coffea arabica extract and labeled from fraction I to VI (PD-1 to PD-6, respectively). The fractions were dried with a rotary evaporator and were assayed for their activities.

\section{DPPH assay procedure}

The antioxidant activity of the extracts was evaluated using DPPH as reported by Shimamura et al. (2014). Various concentrations $(100,50,25$, and $10 \mu \mathrm{g} / \mathrm{mL}$ in $90 \mathrm{v} / \mathrm{v}$ $\%$ ethanol) of each extract ( $1.5 \mathrm{~mL})$ was added to $1.5 \mathrm{~mL}$ of a $0.1 \mathrm{mM}$ solution of DPPH. The mixtures were then left at room temperature for $30 \mathrm{~min}$ in the dark, the absorbance was measured by UV-VIS spectrophotometry at a wavelength of $519 \mathrm{~nm}$. The antioxidant activity was determined by calculating the percentage inhibition (I\%) of DPPH as follows:

$$
\text { DPPH scavenging activity }(\%)=\frac{(A-B)}{A} \times 100
$$

in which, A is the absorbance of the analytical sample, and $\mathrm{B}$ is the absorbance of ethanol solvent. $\mathrm{IC}_{50}$ (inhibitory concentration of $50 \%$ ) values were calculated from the interpolation method. Gallic acid as a positive control was used at various concentrations (1.0, 2.5, 5.0, and 
$10.0 \mu \mathrm{M})$.

\section{Ferric reducing/antioxidant power (FRAP) assay}

The ferric reducing ability of the samples was evaluated according to the modified method of Labiad et al. (2017). According to the method, the antioxidant activity is evaluated based on the capacity to reduce ferric (III) iron to ferrous (II) iron by the action of electron-donating antioxidants. Extracts $(0.1,0.5$, and $1.0 \mathrm{mg}$ ) were mixed with $1 \mathrm{~mL}$ of potassium phosphate buffer $(2.0 \mathrm{M}, \mathrm{pH} 6.6)$ and $1 \mathrm{~mL}$ of potassium ferricyanide $\left[\mathrm{K}_{3} \mathrm{Fe}(\mathrm{CN})_{6}\right] 1 \%(\mathrm{w} / \mathrm{w})$. The mixture was incubated for $20 \mathrm{~min}$ at $50^{\circ} \mathrm{C}$. An aliquot $(1 \mathrm{~mL})$ of $10 \%(\mathrm{w} / \mathrm{w})$ TCA was added to the mixture, which was then centrifuged at 2,000 rpm for 10 min. The supernatant $(1 \mathrm{~mL})$ was mixed with $1 \mathrm{~mL}$ of distilled water and $0.2 \mathrm{~mL}$ of ferric chloride $0.1 \%$. The absorbance of this solution was measured at $700 \mathrm{~nm}$.

\section{Determination of total phenolic content}

Total phenolic content of extracts was determined using the Folin-Ciocalteu method with slight modification (Ainsworth and Gillespie, 2007). The test sample $(60 \mu \mathrm{L})$ was mixed with $1 \mathrm{~mL}$ of the reagent solution $(1: 5 \mathrm{v} / \mathrm{v})$ within $5 \mathrm{~min}$. Then, $0.7 \mathrm{~mL}$ of $1.0 \mathrm{M}$ sodium carbonate was added to the mixture and brought to $3 \mathrm{~mL}$ with distilled water. The solution was left for $30 \mathrm{~min}$ at room temperature in the dark and its absorbance was measured at $770 \mathrm{~nm}$ using a Hitachi UH-530 spectrophotometer (Hitachi, Ltd., Tokyo, Japan). The total phenolic content was calculated as mg gallic acid equivalent per gram of extract (mgGAE/g) from the gallic acid calibration curve.

\section{Determination of tyrosinase inhibitory activity}

Tyrosinase inhibitory activity was determined based on a modification of Tadtong et al. (2009). Initially, $40 \mu \mathrm{L}$ of extract solution (dissolved in phosphate buffer, $\mathrm{pH}$ 6.8) at concentrations of $100,75,50,25$, and $5 \mu \mathrm{g} / \mathrm{mL}$ and 20 $\mu \mathrm{L}$ of tyrosinase (100 units $/ \mathrm{mL}$ ) was applied to a 96 -well plate. This reaction mixture was mixed thoroughly and incubated for $30 \mathrm{~min}$ at room temperature. Then, $140 \mu \mathrm{L}$ of $0.714 \mathrm{mM} \mathrm{L-DOPA}$ (as substrate at $45^{\circ} \mathrm{C}$ ) was added to initiate the reaction. After incubation for $3 \mathrm{~min}$, the difference in absorbance at $475 \mathrm{~nm}$ was measured, compared to the control consisting of phosphate buffer (50 $\mathrm{mM}, \mathrm{pH}$ 6.8) instead of tyrosinase. Kojic acid at various concentrations $(1,2.5,5$, and $10 \mu \mathrm{M})$ was used as a positive control. The percentage of tyrosinase inhibition (I\%) and $\mathrm{IC}_{50}$ value were calculated in a similar manner as the DPPH assay.

\section{Shrimp preparation and treatment}

Freshly captured whiteleg shrimp (Litopenaeus vannamei) free of additives, with the size of 30 40 shrimp $/ \mathrm{kg}$ were bought alive from a local market in Ho Chi Minh City,
Viet Nam. The shrimp were handled carefully by placing in polystyrene boxes filled with ice [shrimp/ice ratio 1:2 $(\mathrm{w} / \mathrm{w})]$, and were immediately transported to the chemical technology laboratory, Ho Chi Minh City University of Technology and Education, Ho Chi Minh City, Viet Nam. On the way to the laboratory, shrimp were washed with cold water and kept in ice before experiments were done within $1 \mathrm{~h}$. The shrimp samples were divided into 4 equal parts. Each part was dipped into the Coffea arabica sediment extract solution, the PD-3 solution, the sodium metabisulfite (SMS) solution $1.25 \%$, and water (as the control), respectively, in the ratio of 1:2 (shrimp : solution, w/v) at $4^{\circ} \mathrm{C}$ for $15 \mathrm{~min}$. After removal from the solutions, shrimp were left on plastic sieves at $4^{\circ} \mathrm{C}$ for 5 min. The shrimp were placed in polypropylene boxes and kept in a refrigerator at $4^{\circ} \mathrm{C}$ for subsequent quality assessments: $\mathrm{pH}$ changes, melanosis development, bacterial count, lipid peroxidation, and microbiological analysis. Samples were taken for analyses at an interval of 1 day up to 7 days during 7 days of storage.

\section{pH measurement}

$\mathrm{pH}$ measurement was determined by the method described by Chouljenko et al. (2017). Two grams of shrimp were homogenized with $10 \mathrm{~mL}$ of deionized water in a beaker for $1 \mathrm{~min}$. The mixture was stored for $5 \mathrm{~min}$ at room temperature. The $\mathrm{pH}$ values of all samples were measured using a pH-meter ( $\mathrm{pH}$ 1200, PSI, Guildford, $\mathrm{UK})$. All measurements were carried out in triplicate.

\section{Melanosis evaluation}

The photos of shrimp samples were taken by a digital camera (Eos M10 Kit Ef-M15-45, Canon, Tokyo, Japan). Relative changes in the gray value of the shrimp carapace were calculated by the following formula:

$$
\% \text { Relative change }=100-\frac{\mathrm{A} \times 100}{\mathrm{~B}}
$$

which A is the actual gray value of the sample, and B is the average gray value of the shrimp on the first day (Encarnacion et al., 2012). The color image analysis was conducted using ImageJ software (NIH, Bethesda, MD, USA). Low mean gray values indicated the formation of melanosis in the carapace of shrimp.

\section{Lipid peroxidation inhibitory assay}

The extent of lipid oxidation was determined using thiobarbituric acid reactive substances (TBARS). Thiobarbituric acid (TBA) reacts with malonaldehyde bis (dimethyl acetal) (MDA) in acidic conditions to form a pink MDA-(TBA) $)_{2}$ complex, which can be quantified at 532 $\mathrm{nm}$ by a spectrophotometer (Sochor et al., 2012). A portion $(5 \mathrm{~g})$ of ground shrimp was homogenized with 10 
$\mathrm{mL}$ of TCA $(7.5 \%, \mathrm{w} / \mathrm{w})$. The mixture was filtered, the filtrate was mixed with an equal volume of $0.02 \mathrm{M}$ TBA and incubated at $100^{\circ} \mathrm{C}$ for $15 \mathrm{~min}$. The absorbance at $532 \mathrm{~nm}$ was measured with Hitachi UH-530 spectrophotometer (Hitachi, Ltd.). TBARS values were calculated from the calibration curve built at concentrations from 0.01 to $0.05 \mu \mathrm{M}$ and reported as malondialdehyde equivalents (mgMAD/kg of shrimp).

\section{Microbiological analyses}

The microbiological quality of shrimp samples was assessed based on the bacterial count method in three parameters: total plate count (ISO, 2013), Enterobacteriaceae count (EBC) (ISO, 2017), and Pseudomonas aeruginosa count (Decision No. 3347/2001/QĐ-BYT). All experiments were conducted at Center of Analytical Services and Experimentation HCM (Ho Chi Minh City, Viet Nam). Microbial colonies were counted and reported as $\log$ colony-forming unit (CFU)/g fresh weight.

\section{Physicochemical analyses}

Protein content of all samples was tested according to AOAC (1992). All determinations were carried out at Center of Analytical Services and Experimentation HCM (CASE, Ho Chi Minh City, Viet Nam).

The shear force of shrimp during 7 days of storage was measured by the Rheo Tex SD 700II analyzer (Sun Scientific Co., Ltd., Tokyo, Japan) at Research Institute for Aquaculture No 2 (RIA2, Ho Chi Minh City, Viet Nam). The operating parameter used was the cross head speed of $10 \mathrm{~mm} / \mathrm{s}$. The shear force perpendicular to the axis of the second segment muscle fibers, was measured.

Total volatile basic nitrogen (TVB-N) was measured according to Vietnamese National Standards TCVN 9215 (TCVN, 2012) at Center of Analytical Services and Experimentation HCM (CASE, Ho Chi Minh City, Viet Nam). The TVB-N values were expressed as mg N/100 g of shrimp meat.

\section{Statistical analysis}

Results were analyzed by analysis of variance (ANOVA) while means were tested with Tukey's test $(P<0.05)$ for three determinations. Statistical data were performed using an SPSS package (SPSS 20 for Windows Evaluation Version, IBM Corporation, Armonk, NC, USA).

\section{RESULTS AND DISCUSSION}

\section{DPPH radical scavenging activity}

The results for DPPH radical scavenging activity were summarized in Table 1 . The lower IC $_{50}$ value indicates higher antioxidant capacity. Among the fractions screened for the DPPH assay, PD-3 was the most active sample with an $\mathrm{IC}_{50}$ value of $27.3 \mu \mathrm{g} / \mathrm{mL}$, followed by CE with $\mathrm{IC}_{50}$ of $32.2 \mu \mathrm{g} / \mathrm{mL}(P<0.05)$. The second group was composed of PD-1, PD-2, and PD-4 with moderate antioxidant activity, and their $\mathrm{IC}_{50}$ values were in the range of $51.1 \sim 79.2 \mu \mathrm{g} / \mathrm{mL}$. Weak antioxidant activity was observed for the remaining 2 fractions with $\mathrm{IC}_{50}$ values of more than $100 \mu \mathrm{g} / \mathrm{mL}$. All IC 50 values for samples were lower than that of the positive control, gallic acid $\left(\mathrm{IC}_{50}\right.$ value of $7.18 \mu \mathrm{g} / \mathrm{mL}$ ). The hydrogen atom or electrondonating abilities of compounds to reduce the free radical DPPH to a stable form may explain the antioxidant activity of the fractions (Sharma et al., 2007).

\section{Tyrosinase inhibitory activity}

For antityrosinase activity, the study demonstrated that all fractions exhibited inhibition to varying degrees at the concentration of $100 \mu \mathrm{g} / \mathrm{mL}(P<0.05)$ (Table 1$)$. It should be noted that PD-4 possessed the lowest tyrosinase inhibitory activity with I\% value of 60.5 whilst the PD-3 had the strongest inhibitory activity with I\% value of 79.5 , which could be applied as a natural anti-browning agent $(P<0.05)$. The $\mathrm{CE}$ was ranked second with $\mathrm{I} \%$ value of 75.6 among screened samples. Kojic acid, used as a stand-

Table 1. Antioxidant and tyrosinase activities of crude extract (CE) and different fractions from Coffea arabica

\begin{tabular}{|c|c|c|c|c|c|c|c|}
\hline \multirow{2}{*}{ No } & \multirow{2}{*}{ Sample } & \multirow{2}{*}{$\begin{array}{c}\mathrm{DPPH}\left(\mathrm{IC}_{50}\right) \\
(\mu \mathrm{g} / \mathrm{mL})\end{array}$} & \multirow{2}{*}{$\begin{array}{l}\text { Total phenolic } \\
\text { content } \\
\text { (mgGAE/100 g) }\end{array}$} & \multirow{2}{*}{$\begin{array}{l}\text { Tyrosinase } \\
\text { inhibition } \\
\text { activity (I\%) } \\
(100 \mu \mathrm{g} / \mathrm{mL})\end{array}$} & \multicolumn{3}{|c|}{ FRAP } \\
\hline & & & & & $0.1 \mu \mathrm{g} / \mathrm{mL}$ & $0.5 \mu \mathrm{g} / \mathrm{mL}$ & $1.0 \mu \mathrm{g} / \mathrm{mL}$ \\
\hline 1 & CE & $32.2 \pm 0.4^{\mathrm{e}}$ & $109.1 \pm 0.8^{b}$ & $75.6 \pm 0.3^{b}$ & $0.721 \pm 0.002^{b}$ & $2.334 \pm 0.002^{c}$ & $3.663 \pm 0.002^{b}$ \\
\hline 2 & PD-1 & $51.1 \pm 0.3^{d}$ & $89.2 \pm 0.3^{d}$ & $70.9 \pm 0.1^{c}$ & $0.362 \pm 0.005^{f}$ & $2.377 \pm 0.003^{a}$ & $3.563 \pm 0.003^{d}$ \\
\hline 3 & PD-2 & $62.0 \pm 0.5^{c}$ & $105.1 \pm 0.2^{c}$ & $66.7 \pm 0.2^{\mathrm{e}}$ & $0.679 \pm 0.002^{c}$ & $2.362 \pm 0.004^{b}$ & $3.578 \pm 0.003^{c}$ \\
\hline 4 & PD-3 & $27.3 \pm 0.2^{f}$ & $116.5 \pm 0.4^{a}$ & $79.5 \pm 0.3^{a}$ & $0.793 \pm 0.002^{a}$ & $2.316 \pm 0.002^{d}$ & $3.702 \pm 0.004^{a}$ \\
\hline 5 & PD-4 & $79.2 \pm 0.6^{b}$ & $79.7 \pm 0.5^{f}$ & $60.5 \pm 0.2^{g}$ & $0.650 \pm 0.003^{d}$ & $1.894 \pm 0.002^{g}$ & $3.361 \pm 0.003^{f}$ \\
\hline 6 & PD-5 & $>100^{a}$ & $75.1 \pm 0.4^{9}$ & $67.9 \pm 0.1^{d}$ & $0.302 \pm 0.002^{g}$ & $1.954 \pm 0.001^{f}$ & $3.117 \pm 0.002^{g}$ \\
\hline 7 & PD-6 & $>100^{a}$ & $83.1 \pm 0.5^{\mathrm{e}}$ & $64.7 \pm 0.3^{f}$ & $0.564 \pm 0.001^{\mathrm{e}}$ & $2.235 \pm 0.002^{\mathrm{e}}$ & $3.510 \pm 0.002^{\mathrm{e}}$ \\
\hline
\end{tabular}

Values represent the mean \pm standard deviation $(n=3)$.

Means with different letters $(a-g)$ in each column indicate significant differences $(P<0.05)$ according to Tukey's test.

Fractions collected from the fractionation process of Coffea arabica extract and labeled from fraction I to VI (PD-1 to PD-6, respectively). 
ard inhibitor, had I\% value of 89.91 .

The presence of phenolic compounds especially flavonoids may be responsible for the tyrosinase inhibition. Plant polyphenols possessing a similar structure as the substrate (L-DOPA) are usually strong inhibitors. Specifically, flavonoids containing an $\alpha$-keto group show high inhibition because of the similarity between the dihydroxyphenyl group in L-DOPA and the $\alpha$-keto group in flavonoids. These polyphenols are able to chelate copper atoms in the active site of tyrosinase (Kim and Uyama, 2005).

\section{FRAP assay}

The reducing power (RP) assay is widely used to evaluate the ability of an antioxidant to donate an electron. It was reported that the reducing power of extracts indicate their potential antioxidant activity. Antioxidants in the samples reduced the ferric cyanide complex $\left(\mathrm{Fe}^{3+}\right)$ to the ferrous cyanide form $\left(\mathrm{Fe}^{2+}\right)$ (Yang et al., 2014). A higher value in absorbance indicates greater reducing capacity. Table 1 demonstrates that RP was directly proportional to the concentration of samples and was found to increase with the increase in concentration. Of these surveyed samples, the highest RP was observed to be in the order of PD-3> CE $>$ PD-2 $>$ PD-1 $>$ PD-6 at $1.0 \mu \mathrm{g} / \mathrm{mL}$ of extract $(P<0.05)$. The results indicate that the ferric reducing power was generally correlated with the total phenolic content and the DPPH radical scavenging activity.

\section{Total phenolic content}

The total phenolic content of the six fractions and $\mathrm{CE}$ varied in wide ranges from $75.1 \mathrm{mgGAE} / \mathrm{g}$ (PD-5) to 116.5 mgGAE/g (PD-3) (Table 1). As shown in the Table 1 , all samples demonstrated high content of total phenolics with values of more than $75.0 \mathrm{mgGAE} / \mathrm{g}$. Of these, the maximum phenolic content was found in the PD-3 fraction (116.5), followed by the $\mathrm{CE}$ with the content of $109.1 \mathrm{mgGAE} / \mathrm{g}$.

Many studies have reported that the total phenolic content has been correlated with antioxidant activity of plant fractions, owing to the redox properties of phenolic compounds acting as reducing agents, hydrogen donors, or metal chelators (Pereira et al., 2015). To summarize, high DPPH radical scavenging and tyrosinase inhibition of the Coffea arabica extract suggested that the extract could be potentially used as an antioxidant and melanosis inhibitor. The biological activities of plant samples are caused by the presence of chemical substances called phytochemicals, so the investigation for the phytochemicals of the fraction is essential (Rakholiya et al., 2016).

From the above results, PD-3 had the best antioxidant and antityrosinase activities. Therefore, PD-3 was chosen, among all fractions, to serve as a promising source of natural preservative for the storage of shrimp.

\section{pH measurement}

Changes in $\mathrm{pH}$ of whiteleg shrimp with different treatments: PD-3, CE, and SMS during refrigerated storage compared with the control (immersed in distilled water) are shown in Fig. 1. Overall, the $\mathrm{pH}$ for all shrimp samples saw an upward trend $(P<0.05)$ over storage, while the $\mathrm{pH}$ for $\mathrm{PD}-3$ treatment experienced lower $\mathrm{pH}$ values thru storage. After 7 days of storage, $\mathrm{pH}$ values of all samples rose approximately $12 \%$ with the notable exception of the shrimp treated with PD-3, where the $\mathrm{pH}$ increased at the lowest level at $8.5 \%$. During the first two days of storage, no significant differences were observed among $\mathrm{pH}$ values for all treatments $(P>0.05)$. From day 2 onwards, the lowest $\mathrm{pH}$ was found in the PD-3 batches, followed by the CE and SMS treatment batches $(P<0.05)$. Final values of 7.78 and 7.69 were observed in the control and SMS samples, respectively; 7.60 and 7.46 were

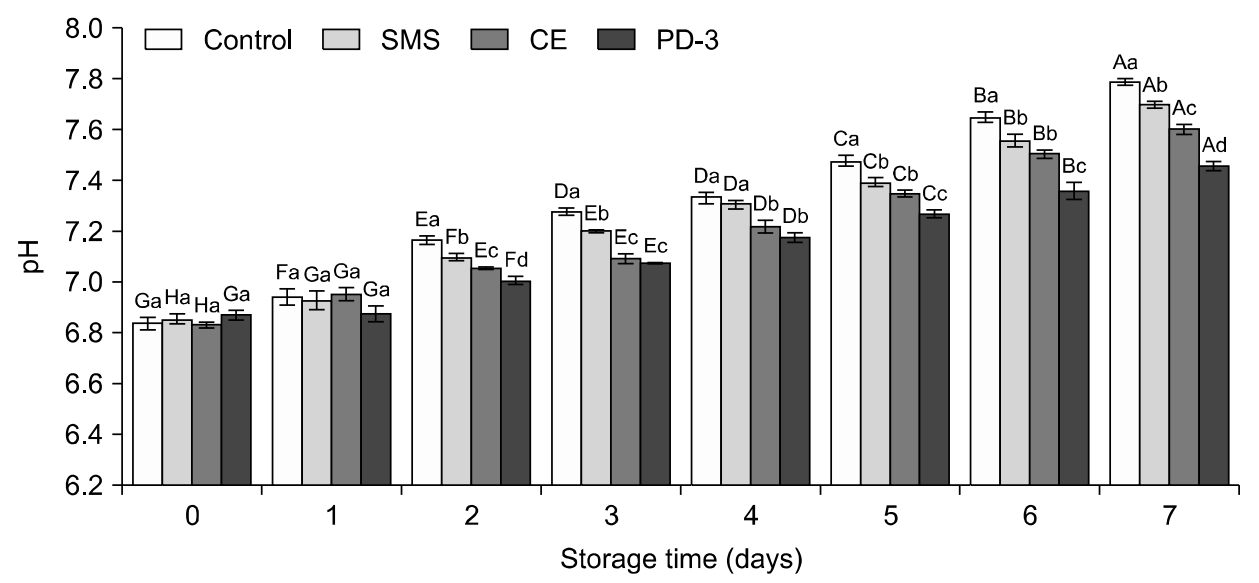

Fig. 1. Changes in $\mathrm{pH}$ of whiteleg shrimp, Litopenaus vannamei during refrigerated storage. Values represent the mean \pm standard deviation $(n=3)$. Significant differences $(P<0.05)$ among different days of storage in the same treatment are identified with different uppercase letters $(\mathrm{A}-\mathrm{H})$. Significant differences $(P<0.05)$ among different treatments in the same storage time are identified with different lowercase letters (a-d). Control, sample treated water; SMS, sample treated with sodium metabisulfite (1.25\%); CE, sample treated with Coffea arabica extract, PD-3, sample treated with PD-3 fraction obtained from Coffea arabica sediment extract. 
obtained for the CE and PD-3 samples, respectively. $\mathrm{pH}$ change was associated with the accumulative growth of basic compounds, mainly resulting from either endogenous or microbial enzyme actions (Nirmal and Benjakul, 2009; Huang et al., 2012). The lower $\mathrm{pH}$ values for the samples treated with the PD-3 fraction, CE, and SMS followed the lower microbial count. In our study, the lower $\mathrm{pH}$ changes in the PD-3 fraction and CE treatments suggested that these can enhance endogenous or microbial enzyme inhibition.

\section{Melanosis evaluation}

The formation of melanosis in shrimp samples during refrigerated storage, as demonstrated by decreased mean gray values of the carapace of whiteleg shrimp, is illustrated in Fig. 2. Over 7 days of storage, the gray values in all samples indicated a decline, but samples treated with PD-3 and CE changed to a lesser extent than those of the control and $1.25 \% \mathrm{w} / \mathrm{v}$ SMS $(P<0.05)$. At day 0 , all shrimp samples had no differences in gray values $(P<$ $0.05)$. When storage time increased, gray values decreased continuously after 1 and 2 days storage for the control and the SMS samples, respectively, indicating the formation of melanosis, while the CE and PD-3 treatments remained unchanged $(P>0.05)$ until day 2 . After 6 days of storage, the SMS group had severe melanosis as the control including day 7. At the end of the period, the samples treated with PD-3 had the highest gray values, followed by those treated with the CE $(P<0.05)$. These results show that PD-3 and CE retarded the development of melanosis in shrimp. It has been reported that tyrosinase is a copper-containing enzyme catalyzing the synthesis of melanin from tyrosine by oxidation. Some phenolic compounds could inhibit the tyrosinase activity by interacting with the active site of the enzyme through a hydrogen bond or hydrophobic interaction (Kumar et al., 2011).

\section{Lipid peroxidation inhibition assay}

Changes in TBARS values of shrimp samples stored under different conditions during 7 days of storage are presented in Fig. 3. Overall, the PD-3 sample showed the lowest value for TBARS while the highest value was found in the control sample at all storage times $(P<0.05)$. The initial TBARS value of all shrimp samples was about $0.60 \mathrm{mg} \mathrm{MDA} / \mathrm{kg}$ of shrimp $(P>0.05)$, and this value for the control sample rose continuously over the first 6 days while samples with other treatments only followed this rising trend from day 0 to day 3 . During $3 \sim 5$ days of storage, the TBARS values decreased in the PD-3 sample and fluctuated in the CE and the SMS. Within the last 2 days, TBARS levels of all samples followed a similar pattern,
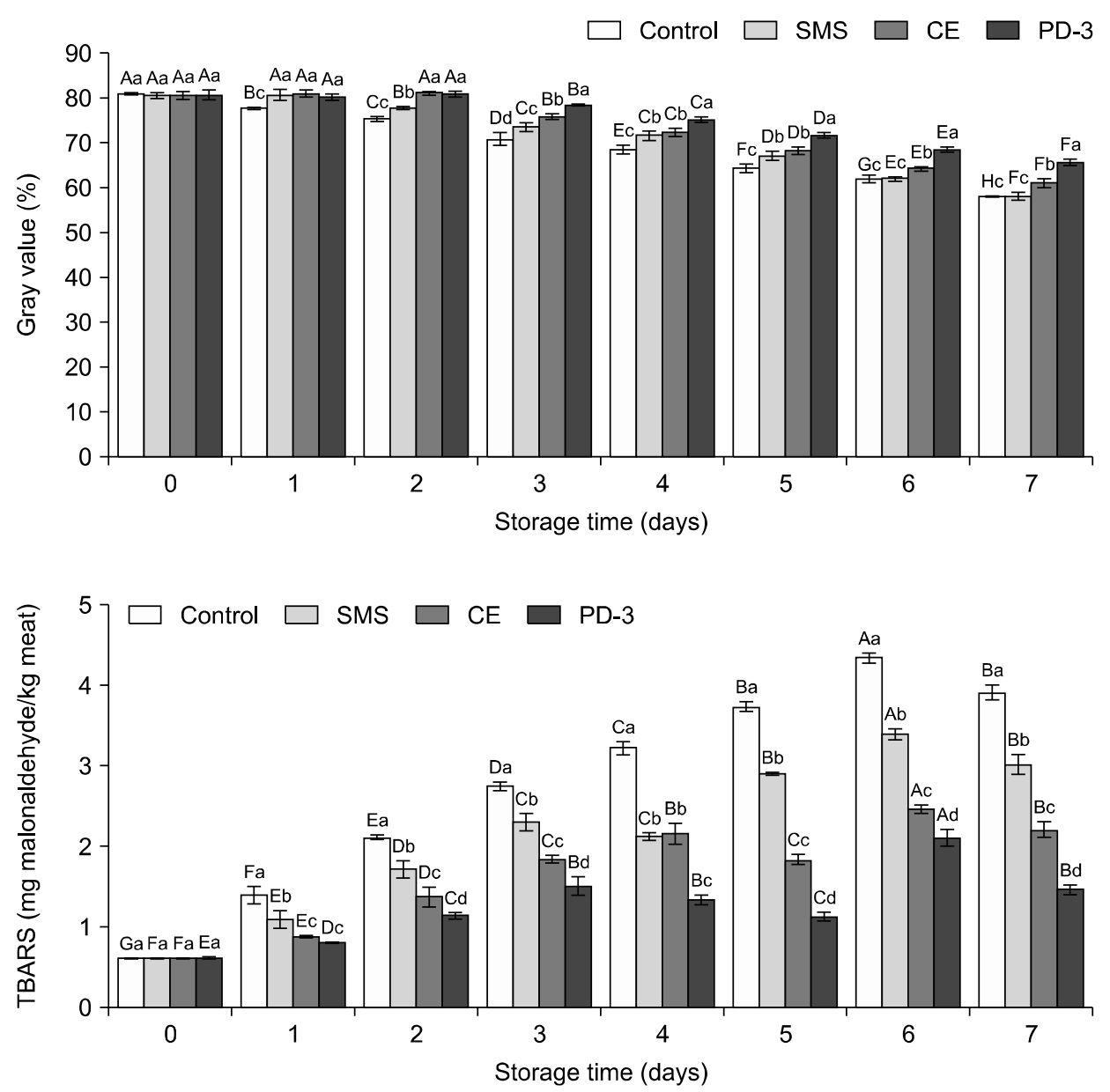

Fig. 2. Changes in the mean gray values of the carapace area of whiteleg shrimp, Litopenaus vannamei during refrigerated storage. Please see Fig. 1 for the caption and legends.

Fig. 3. Changes in the TBARS values of whiteleg shrimp, Litopenaus vannamei during refrigerated storage. Please see Fig. 1 for the caption and legends. 
rising significantly from day 5 to day 6 to peak at 4.33 (mg MDA $/ \mathrm{kg}$ ) for the control, 2.11 for the PD-3, 2.47 for the CE, 3.38 for the SMS, and then declining at day 7 $(P<0.05)$. The increase in TBARS values was reported to involve the formation of secondary lipid oxidation products, mainly aldehydes, from the oxidative degradation of polyunsaturated fatty acids (Papastergiadis et al., 2012), causing off-flavors and off-odors, thereby shortening the shelf life of shrimp (Zhang et al., 2015). The observed decrease in TBARS values was probably because malonaldehyde was metabolized by a large population of spoilage bacteria (Murano et al., 1998). The low TBARS values in the PD-3 and CE samples, compared to other samples, indicated that the PD-3 and CE reduced the lipid oxidation in shrimp during refrigerated storage. A number of studies in the literature have shown that some natural plant extracts could delay lipid oxidation. Nirmal and Benjakul (2012) revealed that whiteleg shrimp treated with green tea extract had lower TBARS content after 12 days of iced storage. A similar finding was shown in the case of shrimp samples stored with pomegranate peel extract, which had significantly lower TBARS values compared with controls after 10 days of refrigerated storage (Basiri et al., 2015). Besides, several antioxidant-rich plant coating materials could protect against lipid oxidation. Greater stability towards lipid oxidation was found when shrimp samples were coated with thymol and basil seed gum (Khazaei et al., 2017), aloe vera, and eugenol (Sharifimehr et al., 2019), green tea extract, and quince seed mucilage (Noshad et al., 2017).

\section{Microbiological analysis}

Microbial spoilage in shrimp after 7 days storage is displayed in Fig. 4. As shown in the Figures, no difference was observed in total plate counts (TPC) (Fig. 4A) and EBC (Fig. 4B) among all samples at day $0(P>0.05)$. Overall, on day 7, TPC and EBC of all shrimp batches were higher than those on day $0(P<0.05)$. Initial TPC of all samples was in the range of 2.80 to $2.85 \log \mathrm{CFU} / \mathrm{g}$ which were in agreement with the values of $2 \sim 3 \log$ CFU/g reported by other authors in good quality pink shrimp (Parapenaeus longirostris) (López-Caballero et al., 2002) and whiteleg shrimp (Litopenaeus vannamei) (Arancibia et al., 2015). After 7 days storage, the TPC of SMS, CE, and PD-4 treatments were 5.53, 5.76, and 5.71, respectively which were lower than control samples (7.34) $(P<0.05)$. According to the TCVN (2006) requirements for frozen aquatic products, the acceptable limit of total aerobic microorganisms is $6.0 \log \mathrm{CFU} / \mathrm{g}$. It is clear that all microbial counts for SMS, CE, and PD-3 samples were below this limit, while the control sample reached values above the limit.

Noticeably, Pseudomonas aeruginosa counts of all samples were below the detection limit of $1.0 \log \mathrm{CFU} / \mathrm{g}$ at both day 0 and day 7 (data not shown). Shiekh et al. (2019) reported that Pseudomonas counts of whiteleg shrimp treated with chamuang (Garcinia cowa Roxb.) leaf extract were found in the ranges of 2.15 2.18 log CFU/g at the first day of storage and 5.08 6.82 log CFU/g after 10 days of storage. However, counts depend on the environment where shrimp were caught and postmortem conditions (Huang et al., 2012).

In addition, shrimp treated with PD-3 had the lowest EBC of $2.40 \log \mathrm{CFU} / \mathrm{g}$ compared with other samples $(P<0.05)$ during refrigerated storage. Enterobacteriaceae are a large family of Gram-negative bacteria, comprising a number of pathogens such as Salmonella, Klebsiella, Escherichia coli, Shigella, and Yersinia pestis (Posse et al., 2017). The spoilage potential of Enterobacteriaceae must be taken into account particularly in the case of contaminated water or delay in the chilled storage of fish after capture (Sallam, 2007). The results suggest that shrimp treated with Coffea arabica sediment extract and its PD-3 fraction could impede the growth of aerobic microorganisms and
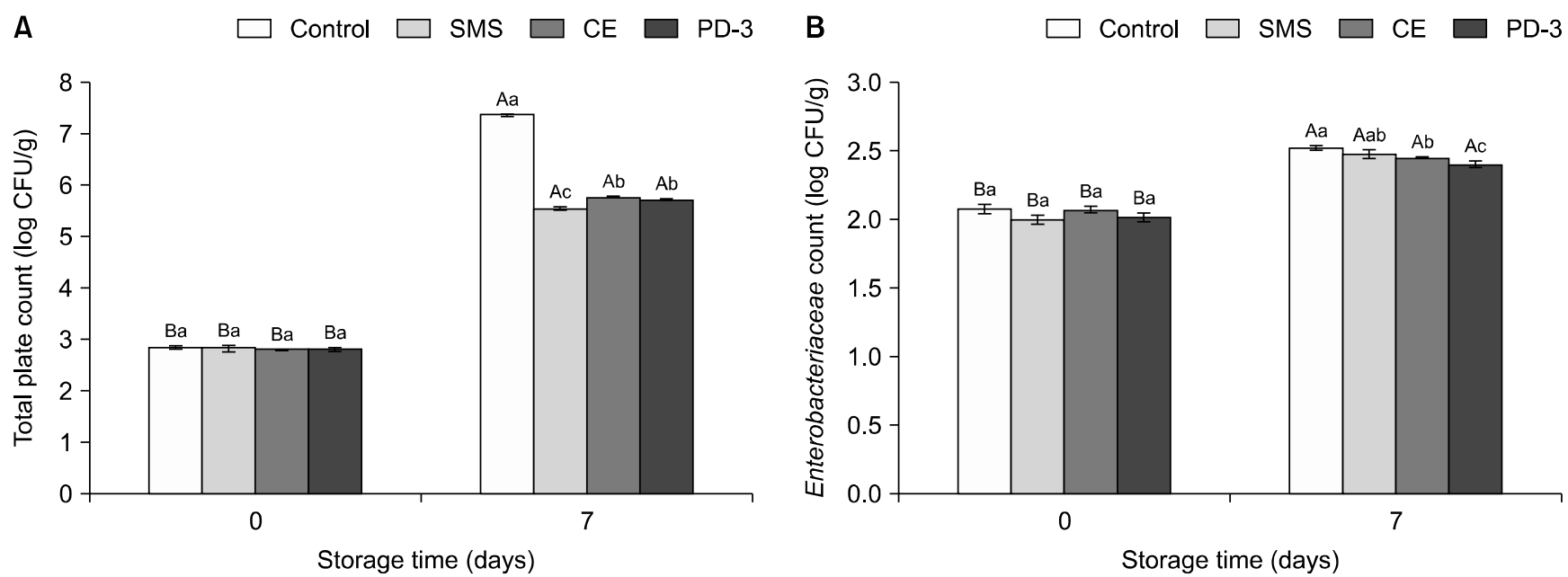

Fig. 4. Total plate (A) and Enterobacteriaceae count (B) of whiteleg shrimp, Litopenaus vannamei during refrigerated storage. Please see Fig. 1 for the caption and legends. 
lower the increase in $\mathrm{EBC}$ during refrigerated storage.

\section{Physicochemical changes}

Physicochemical parameters of shrimp samples, namely protein content, shear force and TVB-N after 7 days of storage were determined and shown in Fig. 5, Fig. 6, and Fig. 7.

The results show that the protein content of shrimp stored with PD-3 and CE were similar to shrimp stored with SMS, in the range of $21.3 \sim 22.3(P>0.05)$ and higher than that of control $(P<0.05)$, indicating that $\mathrm{CE}$ and PD-3 reduced protein loss and that they could replace SMS in shrimp storage (Fig. 5). Pan et al. (2019) demonstrated that the release of proteolytic enzymes like cathepsins and calcium-dependent proteases may result in decreases in myofibrillar and intramuscular tissue, leading to the deterioration of shrimp muscle protein. Not much information is available on the changes of shrimp protein content during low-temperature storage. Kamal et al. (2000) reported that the protein content of giant freshwater prawn, Macrobrachium rosenbergii, and tiger shrimp, Penaeus monodon, decreased from 18.46 to 17.05 $\%$ and 18.06 to $16.85 \%$, respectively during 10 days of iced storage.

Fig. 6 illustrates that all samples had a similar shear force in the range of 19.8 20.0 N $(P>0.05)$ at day 0 . Higher shear force values of muscle for samples treated with PD-3, CE, and SMS were observed as compared to those of control samples after 7 days storage $(P<0.05)$. It is noted that the higher shear force of the samples in treatment batches was consistent with the lower microbial load, demonstrating that the inhibitory activity of CE and PD-3 for the microbial growth might limit proteinases and collagenase which are responsible for the degradation of muscle protein in shrimp (Nirmal and Benjakul, 2009). The texture changes of shrimp could be affected by many vital factors, such as $\mathrm{pH}$, or degradation

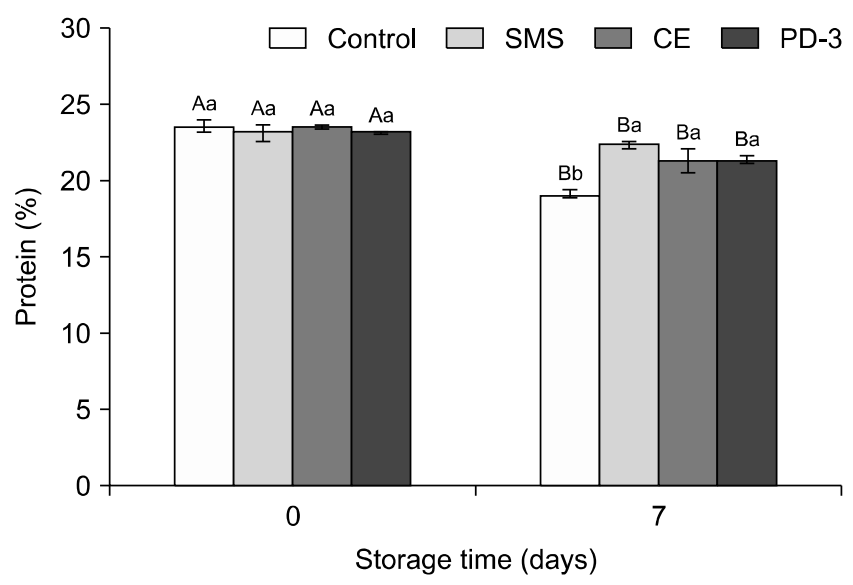

Fig. 5. Protein content of whiteleg shrimp, Litopenaus vanname, during refrigerated storage. Please see Fig. 1 for the caption and legends. of connective tissue or myofibrillar proteins (Yuan et al., 2016a). The results of this study are similar to a previous report by Nirmal and Benjakul (2009), which indicated that shrimp treated with $0.05 \%$ catechin and $0.1 \%$ catechin had higher shear force values as compared to the control after 10 days of iced storage. The retardation of texture loss was reported when Pacific white shrimp (Litopenaeus vannamei) was coated with chitosan in combination with pomegranate peel extract (Yuan et al., 2016a), chitosan-carvacrol (Wang et al., 2018), or chitosan-gelatin (Farajzadeh et al., 2016).

TVB-N is commonly used to determine the quality and freshness of seafood products and is indicative of microbial and chemical spoilage (Huang et al., 2012). The increase in TVB-N results from the degradative process of nitrogenous compounds in the muscle like proteins, amino acids, peptides, and nucleotides caused by the activity of endogenous enzymes and spoilage bacteria (Pan et al., 2019). Fig. 7 indicates the results of TVB-N of white-

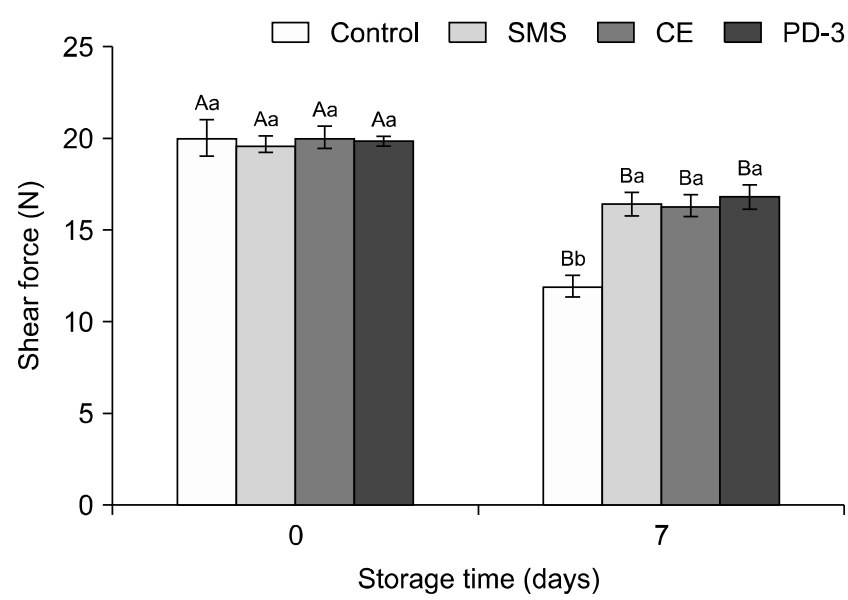

Fig. 6. Shear force of whiteleg shrimp, Litopenaus vannamei during refrigerated storage. Please see Fig. 1 for the caption and legends.

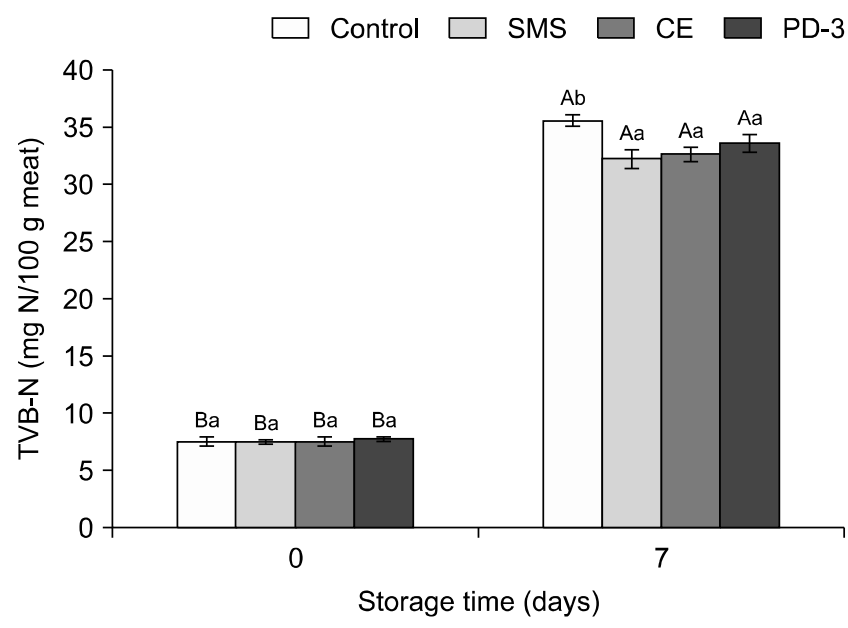

Fig. 7. Total volatile base (TVB-N) content of whiteleg shrimp, Litopenaus vannamei during refrigerated storage. Please see Fig. 1 for the caption and legends. 
leg shrimp during refrigerated storage. Initially, TVB-N (7.6 7.8 mg N/100 g shrimp meat) was not different among all samples $(P>0.05)$. After 7 days of refrigerated storage, shrimp treated with SMS, CE, and PD-3 had similar TVB-N content ranging from 32.2 to $33.6 \mathrm{mg} \mathrm{N} / 100$ g shrimp meat $(P>0.05)$ which were lower than $35.5 \mathrm{mg}$ $\mathrm{N} / 100 \mathrm{~g}$ for the control $(P<0.05)$. Thus, shrimp quality can be improved if it is treated with CE and PD-3, and that TVB-N content correlated well with microbial load in the corresponding samples. Other authors reported a delay in the production of TVB-N in Litopenaeus vannamei shrimp treated with 0.05 or $0.1 \%$ chitosan solution (Nirmal and Benjakul, 2009), coated with 1.0 1.5\% ocarboxymethyl chitosan and 1.0 1.5\% chitosan (Huang et al., 2012), treated with chamuang leaf extract combined with a pulsed electric field (Shiekh et al., 2019), treated with grape seed extracts (Sun et al., 2014), coated with chitosan and pomegranate peel extract (Yuan et al., 2016a), and a chitosan coating supplemented with green tea extract (Yuan et al., 2016b). Concerning the poor data available in the literature, several authors suggested different acceptability limits of TVB-N content. Specifically, TVB content of $30 \mathrm{mg} / 100 \mathrm{~g}$ shrimp meat was indexed for safety and quality acceptability, as proposed by Shiekh et al. (2019) and Huang et al. (2012). However, Altissimi et al. (2017) proposed a higher limit of acceptability at $42 \mathrm{mg} / 100 \mathrm{~g}$ of TVB-N for cephalopods, and Mendes et al. (2002) suggested TVB content of $40 \mathrm{mg} \mathrm{N} / 100 \mathrm{~g}$ as the freshness borderline for shrimp.

In conclusion, the results achieved in this study showed that the extract of Coffea arabica sediment yielded a number of fractions with high anti-tyrosinase and antioxidant activities, high total phenolic content, and high potency for whiteleg shrimp preservation. Coffea arabica sediment and PD-3 treatments were effective in preserving whiteleg shrimp since they lessened melanosis and impeded quality loss during refrigerated storage. Therefore, they can be used as alternatives for sulfite additives, which produce a wide range of negative clinical effects, leading to improving food safety control for the shrimp industry. Use of Coffea arabica sediment extract and the fraction PD-3 will also provide utilization of juice processing byproducts, environmental pollution control, and value addition to the economy.

\section{ACKNOWLEDGEMENTS}

This work belongs to the project grant T2020-15TĐ funded by Ho Chi Minh City University of Technology and Education, Viet Nam. The authors gratefully thank Center of Analytical Services and Experimentation HCM (Ho Chi Minh City, Viet Nam), Research Institute for Aquaculture No. 2 (RIA2, Ho Chi Minh City, Viet Nam) for their valuable cooperation in completion of this research work.

\section{AUTHOR DISCLOSURE STATEMENT}

The authors declare no conflict of interest.

\section{REFERENCES}

AOAC. AOAC Official Method no 992.15. Crude protein in meat and meat products. 1992 [cited 2019 Sep 2]. Available from: http://www.aoacofficialmethod.org/index.php?main_page $=$ product info\&products id $=383$

Ainsworth $\bar{E}$ A, Gillespie KM. Estimation of total phenolic content and other oxidation substrates in plant tissues using FolinCiocalteu reagent. Nat Protoc. 2007. 2:875-877.

Altissimi S, Mercuri ML, Framboas M, Tommasino M, Pelli S, Benedetti F, et al. Indicators of protein spoilage in fresh and defrosted crustaceans and cephalopods stored in domestic condition. Ital J Food Saf. 2017. 6:6921. https://doi.org/10.4081/ ijfs.2017.6921

Arancibia MY, López-Caballero ME, Gómez-Guillén MC, Montero P. Chitosan coatings enriched with active shrimp waste for shrimp preservation. Food Control. 2015. 54:259-266.

Barlow SM. Toxicological aspects of antioxidants used as food additives. In: Hudson BJF, editor. Food Antioxidants. Springer Netherlands, Dordrecht, Netherlands. 1990. p 253-307.

Basiri S, Shekarforoush SS, Aminlari M, Akbari S. The effect of pomegranate peel extract (PPE) on the polyphenol oxidase (PPO) and quality of Pacific white shrimp (Litopenaeus vannamei) during refrigerated storage. LWT-Food Sci Technol. 2015. 60:1025-1033.

Chouljenko A, Chotiko A, Bonilla F, Moncada M, Reyes V, Sathivel $S$. Effects of vacuum tumbling with chitosan nanoparticles on the quality characteristics of cryogenically frozen shrimp. LWT. 2017. 75:114-123.

Decision No.3347/2001/QĐ-BYT. Quantitation of Pseudomonas aeruginosa in food. 2001 [cited 2019 Sep 4]. Available from: https://thuvienphapluat.vn/van-ban/the-thao-y-te/quyet-di nh-3347-2001-qd-byt-thuong-quy-ky-thuat-dinh-luong-truckhuan-mu-xanh-pseudomonas-aeruginosa-trong-thuc-pham69973.aspx?v=d

Encarnacion AB, Fagutao F, Jintasataporn O, Worawattanamateekul W, Hirono I, Ohshima T. Application of ergothioneinerich extract from an edible mushroom Flammulina velutipes for melanosis prevention in shrimp, Penaeus monodon and Litopenaeus vannamei. Food Res Int. 2012. 45:232-237.

Farajzadeh F, Motamedzadegan A, Shahidi SA, Hamzeh S. The effect of chitosan-gelatin coating on the quality of shrimp (Litopenaeus vannamei) under refrigerated condition. Food Control. 2016. 67:163-170.

Gokoglu N, Yerlikaya P. Inhibition effects of grape seed extracts on melanosis formation in shrimp (Parapenaeus longirostris). Int J Food Sci Technol. 2008. 43:1004-1008.

Gowe C. Review on potential use of fruit and vegetables by-products as a valuable source of natural food additives. Food Sci Qual Manage. 2015. 45:47-61.

Huang J, Chen Q, Qiu M, Li S. Chitosan-based edible coatings for quality preservation of postharvest whiteleg shrimp (Litopenaeus vannamei). J Food Sci. 2012. 77:C491-C496.

Hue HT, Tinh HT, Van Bao N, Dao PTA. Screening for antioxidant activity of vegetable and fruit by-products and evaluating the 
ability of coffee sediment to preserve fish meal. SN Appl Sci. 2020. 2:1282. https://doi.org/10.1007/s42452-020-3030-7

ISO. ISO 21528-2:2017. Microbiology of the food chain-horizontal method for the detection and enumeration of Enterobacteriaceae-Part 2: Colony-count technique. 2017 [cited 2019 Sep 5]. Available from: https://www.iso.org/standard/ 63504.html

ISO. ISO 4833-1:2013. Microbiology of the food chain - horizontal method for the enumeration of microorganisms-Part 1: Colony count at $30^{\circ} \mathrm{C}$ by the pour plate technique. 2013 [cited 2019 Sep 5]. Available from: https://www.iso.org/standard/ 53728.html

Jang MS, Sanada A, Ushio H, Tanaka M, Ohshima T. Inhibitory effect of enokitake extract on melanosis of shrimp. Fish Sci. 2003. 69:379-384.

Jayaprakasha GK, Singh RP, Sakariah KK. Antioxidant activity of grape seed (Vitis vinifera) extracts on peroxidation models in vitro. Food Chem. 2001. 73:285-290.

Kamal M, Rahman MM, Yasmin L, Islam MN, Nurullah M, Mazid MA. Studies on the post-mortem changes in shrimp and prawn during ice storage: II. Biochemical aspects of quality changes. Bangladesh J Fish Res. 2000. 4:91-96.

Khazaei N, Esmaiili M, Emam-Djomeh Z. Application of active edible coatings made from basil seed gum and thymol for quality maintenance of shrimp during cold storage. J Sci Food Agric. 2017. 97:1837-1845.

Kim YJ, Uyama H. Tyrosinase inhibitors from natural and synthetic sources: structure, inhibition mechanism and perspective for the future. Cell Mol Life Sci. 2005. 62:1707-1723.

Kodagoda KHGK, Marapana RAUJ. Utilization of fruit processing by-products for industrial applications: a review. Int J Food Sci Nutr. 2017. 2:24-30.

Kuijpers TF, Gruppen H, Sforza S, van Berkel WJ, Vincken JP. The antibrowning agent sulfite inactivates Agaricus bisporus tyrosinase through covalent modification of the copper-B site. FEBS J. 2013. 280:6184-6195.

Kumar CM, Sathisha UV, Dharmesh S, Rao AG, Singh SA. Interaction of sesamol (3,4-methylenedioxyphenol) with tyrosinase and its effect on melanin synthesis. Biochimie. 2011. 93:562569.

Labiad MH, Harhar H, Ghanimi A, Tabyaoui MH. Phytochemical screening and antioxidant activity of Moroccan Thymus satureioïdes extracts. J Mater Environ Sci. 2017. 8:2132-2139.

López-Caballero M, Gonçalves A, Nunes M. Effect of $\mathrm{CO}_{2} / \mathrm{O}_{2}-$ containing modified atmospheres on packed deepwater pink shrimp (Parapenaeus longirostris). Eur Food Res Technol. 2002. 214:192-197.

Mendes R, Huidobro A, Caballero E. Indole levels in deepwater pink shrimp (Parapenaeus longirostris) from the Portuguese coast. Effects of temperature abuse. Eur Food Res Technol. 2002. 214:125-130.

Murano PS, Murano EA, Olson DG. Irradiated ground beef: sensory and quality changes during storage under various packaging conditions. J Food Sci. 1998. 63:548-551.

Na S, Kim JH, Jang HJ, Park HJ, Oh SW. Shelf life extension of Pacific white shrimp (Litopenaeus vannamei) using chitosan and $\varepsilon$-polylysine during cold storage. Int J Biol Macromol. 2018. 115:1103-1108.

Nirmal NP, Benjakul S. Effect of green tea extract in combination with ascorbic acid on the retardation of melanosis and quality changes of pacific white shrimp during iced storage. Food Bioprocess Technol. 2012. 5:2941-2951.

Nirmal NP, Benjakul S. Melanosis and quality changes of Pacific white shrimp (Litopenaeus vannamei) treated with catechin during iced storage. J Agric Food Chem. 2009. 57:3578-3586.

Noshad M, Nasehi B, Anvar A. Effect of active edible coating made by quince seed mucilage and green tea extract on quality of fried shrimps: physicochemical and sensory properties. Nutr Food Sci Res. 2017. 4:31-36.

Pan C, Chen S, Hao S, Yang X. Effect of low-temperature preservation on quality changes in Pacific white shrimp, Litopenaeus vannamei: a review. J Sci Food Agric. 2019. 99:6121-6128.

Papastergiadis A, Mubiru E, Van Langenhove H, De Meulenaer B. Malondialdehyde measurement in oxidized foods: evaluation of the spectrophotometric thiobarbituric acid reactive substances (TBARS) test in various foods. J Agric Food Chem. 2012. 60:9589-9594.

Pereira VV, Borel CR, Silva RR. Phytochemical screening, total phenolic content and antioxidant activity of Byrsonima species. Nat Prod Res. 2015. 29:1461-1465.

Posse JL, Dios PD, Scully C. Systemic bacteria transmissible by kissing. In: Saliva Protection and Transmissible Diseases. Academic Press, London, UK. 2017. p 29-51.

Rakholiya K, Kaneria M, Chanda S. Physicochemical and phytochemical analysis of different parts of Indian kesar mango-a unique variety from Saurashtra region of Gujarat. Pharmacog J. 2016. 8:502-506.

Sallam KI. Antimicrobial and antioxidant effects of sodium acetate, sodium lactate, and sodium citrate in refrigerated sliced salmon. Food Control. 2007. 18:566-575.

Sharifimehr S, Soltanizadeh N, Goli SAH. Physicochemical properties of fried shrimp coated with bio-nano-coating containing eugenol and Aloe vera. LWT. 2019. 109:33-39.

Sharma A, Bhardwaj S, Mann AS, Jain A, Kharya MD. Screening methods of antioxidant activity: an overview. Phcog Rev. 2007. $1: 232-238$

Shiekh KA, Benjakul S, Sae-leaw T. Effect of Chamuang (Garcinia cowa Roxb.) leaf extract on inhibition of melanosis and quality changes of Pacific white shrimp during refrigerated storage. Food Chem. 2019. 270:554-561.

Shimamura T, Sumikura Y, Yamazaki T, Tada A, Kashiwagi T, Ishikawa $\mathrm{H}$, et al. Applicability of the DPPH assay for evaluating the antioxidant capacity of food additives - inter-laboratory evaluation study-. Anal Sci. 2014. 30:717-721.

Sochor J, Ruttkay-Nedecky B, Babula P, Adam V, Hubalek J, Kizek R. Automation of methods for determination of lipid peroxidation. In: Catala A, editor. Lipid Peroxidation. IntechOpen, London, UK. 2012. https://doi.org/10.5772/45945

Sun H, Lv H, Yuan G, Fang X. Effect of grape seed extracts on the melanosis and quality of Pacific white shrimp (Litopenaeus vannamei) during iced storage. Food Sci Technol Res. 2014. 20: 671-677.

Tadtong S, Viriyaroj A, Vorarat S, Nimkulrat S, Suksamrarn S. Antityrosinase and antibacterial activities of mangosteen pericarp extract. J Health Res. 2009. 23:99-102.

Taylor SL, Higley NA, Bush RK. Sulfites in foods: uses, analytical methods, residues, fate, exposure assessment, metabolism, toxicity, and hypersensitivity. Adv Food Res. 1986. 30:1-76.

TCVN. TCVN 5289:2006. Frozen aquatic products - hygienic requirements. 2006 [cited 2019 Sep 6]. Available from: https:// tieuchuan.vsqi.gov.vn/tieuchuan/view? sohieu $=\mathrm{TCVN}+528$ 9\%3A2006

TCVN. TCVN 9215:2012. Fish and fishery products - determination of total volatile basic nitrogen content - . 2012 [cited 2019 Sep 6]. Available from: https://tieuchuan.vsqi.gov.vn/ tieuchuan/view? sohieu $=\mathrm{TCVN}+9215 \% 3 \mathrm{~A} 2012$

Vally $\mathrm{H}$, Misso NL. Adverse reactions to the sulphite additives. Gastroenterol Hepatol Bed Bench. 2012. 5:16-23.

Wang Q, Lei J, Ma J, Yuan G, Sun H. Effect of chitosan-carvacrol coating on the quality of Pacific white shrimp during iced storage as affected by caprylic acid. Int J Biol Macromol. 2018. 106:123-129.

Yang X, Yan F, Huang S, Fu C. Antioxidant activities of fractions from longan pericarps. Food Sci Technol. 2014. 34:341-345. 
Yuan G, Lv H, Tang W, Zhang X, Sun H. Effect of chitosan coating combined with pomegranate peel extract on the quality of $\mathrm{Pa}$ cific white shrimp during iced storage. Food Control. 2016a. 59:818-823.

Yuan G, Zhang X, Tang W, Sun H. Effect of chitosan coating combined with green tea extract on the melanosis and quality of $\mathrm{Pa}$ - cific white shrimp during storage in ice. CyTA-J Food. 2016b. 14:35-40.

Zhang B, Deng S, Wang Q. Chemical changes related to loss of quality in Pacific white shrimp (Litopenaeus vannamei) during chilled storage under slurry ice conditions. J Food Process Preserv. 2015. 39:2507-2515. 